\title{
Early L-carnitine Therapy in Severe Acute Aluminum Phosphide Poisoning: A Randomized Controlled Clinical Trial
}

\author{
Fatma M. Elgazzar', Walaa A. Keshk ${ }^{2}$ and Heba K. Khalifa ${ }^{1 *}$ \\ ${ }^{1}$ Forensic Medicine and Clinical Toxicology Department, Faculty of Medicine, Tanta \\ University, Tanta, Egypt \\ ${ }^{2}$ Department of Medical Biochemistry, Faculty of Medicine, Tanta University, Tanta, \\ Egypt \\ *Correspondence to Heba Kamel Khalifa, dr_hebo_toxo@yahoo.com
}

\section{ABSTRACT}

Introduction: Aluminum phosphide (AlP) is a common solid fumigant pesticide used for agricultural and nonagricultural purposes. In Egypt, AlP tablets are frequently used to commit suicide, and AlP poisoning constituting a frequent cause of admission and mortality in poison control centers. Current management of AlP poisoning is limited to supportive care; as there is no specific antidote. Objectives: to evaluate the therapeutic effect and safety of early L-carnitine administration, as an antioxidant, in treatment of severe acute AlP poisoning. Material and methods: This study was a randomized controlled clinical trial. It was conducted in Tanta Poison Control center (Emergency Hospital, Tanta University). Fifty acute AIP intoxicated patients were randomly allocated into two equal groups A and B using the sequentially numbered, opaque sealed envelopes method. Group A received only the routine treatment. Group B received L - Carnitine therapy as follow: 9 ampoules (9 gm) of L- Carnitine in $500 \mathrm{ml}$ of $0.9 \%$ normal saline given as continuous IV infusion, until improvement or death in addition to the routine treatment. Complete physical examination, routine laboratory investigations and oxidative stress markers; malondialdehyde (MDA), total antioxidant capacity (TAC) and reduced glutathione (GSH) were assessed for each patient. Results: Comparison between groups A and B $12 \mathrm{hrs}$ after admission revealed significant reduction of the mean MDA levels in group B than group A $(7.54 \pm 1.74$ and $16.22 \pm 2.95$ respectively, $\mathrm{p}<0.001)$. At the same time, group B showed significant elevation in the mean TAC $(5.70 \pm 1.55$ and $12.88 \pm 2.49$ respectively) and GSH levels $(2.37 \pm .89,4.09 \pm .86$ respectively). Additionally, the need for intubation and mechanical ventilation was significantly lower in group B compared to group A $(20 \%$ versus $56 \%$ respectively). However, there was non-significant reduction in the number of deaths in patients on L-carnitine therapy (group B) compared with group A $(60 \%$ and $80 \%$ respectively, $\mathrm{p}>0.05)$. Conclusion: Early administration of L-carnitine IV infusion was effective and safe as an adjuvant treatment of AlP poisoned patients.

Keywords: aluminum phosphide; L-carnitine; oxidative stress; malondialdehyde; reduced glutathione; total antioxidant capacity. 


\section{INTRODUCTION:}

Aluminium phosphide (AlP) is a solid fumigant pesticide. It is extensively used in developing countries as a grain preservative. The common use of AlP tablets is due to their low cost, high efficiency, and wide availability (Farahani et al., 2016).

In Egypt, AlP tablets are frequently used to commit suicide especially among teenagers, and AlP poisoning constituting a frequent cause of admission to poison control centers (Badawi et al., 2018). Globally, the annual death rate due to pesticide poisoning is about 300,000. Many of these deaths ensuing from AlP Poisoning. The Mortality rate of AlP poisoning is characteristically high. It may reach $100 \%$ in some poison control centers. Outcome depends on the ingested amount, whether the tablet is fresh or expired, and the time interval between exposure and starting supportive care (Hashemi-Domeneh et al., 2016). Patients mostly die due to cardiovascular collapse, refractory shock, severe acidemia, fulminant hepatic failure, and/or adult respiratory distress syndrome (Navabi et al., 2018). Aluminium phosphide poisoning is typically rapidly progressive. Great numbers of deaths occur in the first 24 hrs, and in severe cases death can occur as early as $3 \mathrm{hrs}$ following toxic exposure. (Farahani et al., 2016).

Following AlP ingestion, it reacts with water and hydrochloric acid in the stomach liberating phosphine (PH3) gas which is absorbed through the gastric mucosa (Navabi et al., 2018). At cellular level, phosphine causes disruption of mitochondrial function. It mostly inhibits cytochrome c oxidase activity (Complex IV) besides disruption of Complex I and Complex II chains.
Finally, ATP formation is highly diminished (Sciuto et al., 2016).

Furthermore, it has been reported that PH3 leads to enhanced production of reactive oxygen species (ROS) and induces oxidative stress through inhibition of enzymatic antioxidants e.g. catalase (CAT), glutathione, glutathione reductase (GR) and superoxide dismutase (SOD). These alterations accelerates lipid peroxidation which result in damage of cell membrane, disruption of ionic barriers, nucleic acid damage, and finally cell death (Gouda et al., 2018).

Current management of AlP poisoning is limited to supportive care; as there is no specific antidote has been determined so far (Dorooshi et al., 2018).

Thus, it is essential to develop beneficial therapeutic interventions based on the proposed mechanisms of phosphine poisoning (Sciuto et al., 2016). As most severe cases presents early by cardiovascular collapse, drugs which work at the mitochondrial level to improve the metabolism of cardiac muscle cells may be a useful aide (Elabbassi et al., 2014).

Successful resuscitation of severe AlP poisoning using aggressive hemodynamic support and L-carnitine has been reported(Elabbassi et al., 2014). Additionally, addition of Lcarnitine therapy to steroids and magnesium sulfate has rescued a case of severe AlP poisoning with an observed rapid reversal of myocardial cell dysfunction (Sumit and Vishnu, 2015).

Considering these favorable reports, the aim of the present study was to evaluate the therapeutic effect and safety of early L-carnitine 
administration, as an antioxidant, in treatment of severe acute AlP poisoning.

\section{MATERIALS\& METHODS}

\section{Study design, setting and ethical considerations:}

This study was a randomized controlled, parallel-group, phase II clinical trial (RCT). The study participants were recruited from Tanta Poison Control center, Emergency Hospital, Tanta University starting from June 2018 till the end of May, 2019. The study was approved by the Research Ethical Committee, Faculty of Medicine, Tanta University. An informed written consent was obtained from each patient or his/her guardians (if the patient was unable to participate in the consent process). Confidentiality of the data was maintained by making a code number for each patient.

\section{Sample size:}

Sample size was calculated by $\mathrm{G}$ power 3.1.9.4 software program depending on the primary outcome. The minimum required sample size per group was 25 according to these assumptions; $\mathrm{p} 1=0.8, \mathrm{p} 2=0.4,5 \%$ margin of error, power of $80 \%$, allocation ratio $1: 1$, and at two-sided hypothesis.

\section{Eligibility criteria:}

\section{Inclusion criteria:}

Patients aged 12 years or older of either sex, presented early within $3 \mathrm{hrs}$ of toxic exposure, with severe symptomatic acute AlP poisoning: Defined by the presence of hemodynamic compromise in the form of systolic blood pressure $<90$ at the time of presentation.

Diagnosis was based on history of exposure including reliable identification of the compound based on the container brought by patient's relatives, suggestive clinical manifestations following shortly a single exposure to AlP tablets, and biochemical detection of phosphine gas in gastric aspirate by silver nitrate test (Chugh et al., 1989).

\section{Exclusion criteria:}

Asymptomatic patients with history of acute aluminum phosphide exposure, co ingestion or exposure to other substances, presence of major medical conditions (e.g. cardiovascular disease, renal or hepatic failure). In addition, patients presented more than 3 hours of having ingested AlP tablets or received treatment for acute AlP poisoning in any medical center before admission. Pregnant and lactating women were also excluded from the study.

\section{Methods:}

Fifty patients were randomly allocated into control (A) and intervention (B) groups (25patients each) by means of the serially numbered, opaque wrapped envelopes method (Doig et al., 2005).

\section{Group A:}

Patients in this group received only the standard treatment of AlP poisoning including care for airway, breathing and 
circulation. Intravenous fluids guided by central venous pressure measurement and vasopressors (Norepinephrine) IV infusion has been used to treat hypotension and refractory shock. Correction of metabolic acidosis by intravenous sodium bicarbonate was also considered. Additionally, magnesium sulfate: $1 \mathrm{~g}$ IV infusion every $1 \mathrm{hr}$ for the first $3 \mathrm{hrs}$, followed by $1-1.5 \mathrm{~g}$ every 6 hrs for 24 hrs was administered. Decontamination was done by gastric lavage using normal saline mixed with sodium bicarbonate solution ( 2 ampoules sodium bicarbonate $25 \%$ added to each $500 \mathrm{cc}$ saline) in all Patients presented within $2 \mathrm{hrs}$ of toxic ingestion. Then, a single $(50 \mathrm{gm})$ dose of activated charcoal was administered (Farahani et al., 2016).

\section{Group B:}

In addition to the conventional treatment described above, patients in this group received L - Carnitine therapy as follow: 9 ampoules (9 gm) of $\mathrm{L}$ carnitine added in $500 \mathrm{ml}$ of $0.9 \%$ normal saline and given as continuous IV infusion, until improvement or death (Sumit and Vishnu, 2015).

The study participants of both groups were subjected to full history taking including age, gender, circumstances of poisoning whether intentional or accidental, amount and route of exposure, time interval between exposure and starting treatment, and history of medical diseases such as liver, renal or cardiac diseases. Additionally, thorough physical examination including vital signs, assessment of level of consciousness by Glasgow coma scale, cardiovascular examination including Electrocardiography (ECG), chest and abdominal examination were done. Immediately after admission and before starting treatment, arterial and venous blood samples were obtained for blood gas analysis and for assessment of the biochemical profile and some oxidative stress biomarkers. These included malondialdehyde (MDA) (Ohkawa et al., 1979), Total antioxidant capacity (TAC)(Koracevic et al., 2001), and reduced glutathione (GSH)(Tietze, 1969) levels . Another venous blood sample was withdrawn to reassess the oxidative stress biomarkers $12 \mathrm{hrs}$ after admission.

All participating patients were prospectively observed until discharge from the hospital or death. Regular measurement and recording of their vital signs, oxygen saturation, and conscious level were done. Occurrence of any adverse effect to drug therapy was documented.

\section{Outcome measures:}

The primary outcome was mortality whereas, ssssecondary outcome measures included the need foiintubation and mechanical ventilation, the recreceived total dose of norepinephrine which was assassessed at the time of discharge, and the length of hospital stay.

\section{Statistics:}

Data were tabulated and analyzed using Statistical Package for the Social Sciences (SPSS) for Windows, version 22.0 (SPSS, Chicago, IL, USA). Shapiro-Wilk test for normality was performed to investigate distribution of quantitative data. For normally distributed data, values were expressed as mean \pm standard deviation and Independent samples $\mathrm{T}$ test was applied. For data that were not normally distributed, median and interquartile range (expressed as $25^{\text {th }}-75^{\text {th }}$ percentiles) 
were calculated and Mann-Whitney U test was used for comparison between the studied groups. Concerning qualitative data, they were expressed as numbers and percentages and Pearson's Chi Square test or Fisher's Exact test when appropriate were used to examine association between two variables. In addition, paired $\mathrm{T}$ test was used to compare oxidative stress biomarkers within each group. Moreover, experimental event rate (EVR) which is

\section{RESULTS}

Table (1) shows baseline demographic, toxicity and clinical characteristics of the study groups at the time of admission. Groups A and B were homogenous with no significant differences concerning age and gender ( $p>0.05)$. All (100\%) patients assumed suicidal ingestion of AlP tablets. The median ingested toxic dose was 1 tablet in both groups, and the median duration between toxic exposure and arrival to hospital was 2 and $1.5 \mathrm{hrs}$ respectively with no significant differences between groups $\mathrm{A}$ and $\mathrm{B}(\mathrm{p}>0.05)$. In addition, distribution of clinical manifestations including consciousness level, vital signs, presence of vomiting and abdominal pain, and ECG evaluation at the time of admission was comparable in both groups $(\mathrm{p}>0.05)$.

Comparison of the routine laboratory investigations of the two studied groups including liver enzymes (ALT and AST), serum creatinine, Blood urea, serum sodium $(\mathrm{Na})$, serum potassium $(\mathrm{K}), \mathrm{PH}, \mathrm{P}_{\mathrm{a}} \mathrm{CO}_{2}, \mathrm{HCO}_{3}$, and $\mathrm{O}_{2}$ saturation demonstrated statistically insignificant difference $(\mathrm{p}>0.05)$ as shown in table (2). the proportion of cases in the intervention group that had the outcome of interest, and absolute risk reduction (ARR) which is the proportion experiencing the event in control group minus the proportion experiencing the event in intervention group were calculated for dichotomous outcome variables. Significance was adopted at $\mathrm{p}$ $<0.05$ for interpretation of results of tests.

Table (3) demonstrates absence of statistically significant differences between groups $\mathrm{A}$ and $\mathrm{B}$ in mean plasma levels of MDA, TAC, and reduced glutathione $(\mathrm{GSH})$ at the time of admission ( $p>0.05)$. Comparison between groups $\mathrm{A}$ and B $12 \mathrm{hrs}$ after admission revealed significant reduction of the mean MDA levels in group B than group A $\begin{array}{llll}7.54 \pm \quad 1.74 & \text { and } 16.22 \pm \quad 2.95\end{array}$ respectively, $\mathrm{p}<0.001)$. At the same time, group B showed significant elevation in the mean TAC $(5.70 \pm 1.55$ and $12.88 \pm 2.49$ respectively) and GSH levels $(2.37 \pm .89,4.09 \pm .86$ respectively). Within group A, comparison of each of the oxidative stress biomarkers at admission and $12 \mathrm{hrs}$ later revealed progressive oxidative stress represented by significant increase in the mean MDA levels $\quad(13.9 \pm \quad 3.0, \quad 16.22 \pm 2.95$ respectively, $\mathrm{p}<.001)$. On the other hand, patients received L-carnitine in group B displayed improvement in the form of significant reduction in the mean MDA levels associated with significant elevation in the mean TAC, and GSH levels $(\mathrm{p}<0.001)$.

Primary and secondary outcomes of the studied groups were illustrated in table (4). There was non-significant reduction in the number of deaths in patients on L-carnitine therapy (group B) compared with group A $(60 \%$ and $80 \%$ 
respectively, $\mathrm{p}>0.05, \quad \mathrm{ARR}=20 \%$ ). Whereas, the need for intubation and mechanical ventilation was significantly lower in group B compared to group A $(20 \%$ versus $56 \%$ respectively, ARR= $36 \%$ and $95 \% \mathrm{CI}=11.01 \%-60.99 \%$ ). The median total amount of norepinephrine administered by patients in groups A and $B$ were comparable with no significant difference between both groups ( $\mathrm{p}=.296$ ) .Concerning the length of hospital stay, patients received L carnitine in group B required a significantly longer duration compared to patients received standard supportive care in group A (the median length of hospital stay was $36 \mathrm{hrs}$ vs 14 hrs respectively, $\mathrm{p}=.028$ ).

Survivors of group B showed significantly lower median duration of hospital stay compared to group A (44 hrs vs 99 hrs respectively, $\mathrm{p}=.001$ )
(Table 5). In addition, comparison of non-survivors in both groups revealed a statistically significant reduction in the rate of intubation and mechanical ventilation in patients of group B $(26.7 \%$ vs $65.0 \%$ respectively, $\mathrm{ARR}=38.33 \%$, CI=7.71\%-68.96\%), but these patients (group B) needed a significantly longer duration of hospital stay (median stay was $23 \mathrm{hrs}$ vs $12 \mathrm{hrs}$ respectively) (Table $6)$.

Silver nitrate test was done to confirm diagnosis and it was positive in all $(100 \%)$ the studied patients. Additionally, meticulous follow up of patients received L-carnitine therapy (Group B) did not show any major adverse effects in comparison with patients received only the standard management (Group A).

Table (1): Base line demographic, toxicity, clinical, and ECG characteristics of the study groups $(\mathrm{n}=50)$

\begin{tabular}{|c|c|c|c|c|c|c|c|}
\hline & \multicolumn{4}{|c|}{ Groups } & \multicolumn{2}{|c|}{$\begin{array}{c}\text { Tests of } \\
\text { significance }\end{array}$} \\
\hline & & \multicolumn{2}{|c|}{$\begin{array}{c}\text { Supportive } \\
\mathrm{A}(\mathrm{n}=25)\end{array}$} & \multicolumn{2}{|c|}{$\begin{array}{l}\text { Intervention } \\
\mathrm{B}(\mathrm{n}=25)\end{array}$} & $\begin{array}{c}\text { Test } \\
\text { statist }\end{array}$ & $\begin{array}{c}\mathrm{P} \\
\text { valu }\end{array}$ \\
\hline Age (Years) & Mean \pm SD & \multicolumn{2}{|c|}{$23.9 \pm 7.6$} & \multicolumn{2}{|c|}{$22.9 \pm 7.8$} & .422 & .66 \\
\hline \multirow[t]{2}{*}{$\operatorname{Sex} N(\%)$} & Female & 14 & 56.0 & 15 & $60.0 \%$ & \multirow[t]{2}{*}{.082} & \multirow{2}{*}{$\begin{array}{c}.77 \\
4\end{array}$} \\
\hline & Male & 11 & $\begin{array}{c}44.0 \\
\%\end{array}$ & 10 & $40.0 \%$ & & \\
\hline Toxic dose (tablet) & Median (IQR) & \multicolumn{2}{|c|}{$\begin{array}{c}1.0(1.0- \\
1.0)\end{array}$} & \multicolumn{2}{|c|}{$1.0(0.5-1.0)$} & .126 & $\begin{array}{c}.89 \\
9\end{array}$ \\
\hline $\begin{array}{l}\text { Duration between } \\
\text { exposure and arrival } \\
\text { to hospital (h) }\end{array}$ & Median (IQR) & \multicolumn{2}{|c|}{$\begin{array}{c}2.0(2.0- \\
2.0)\end{array}$} & \multicolumn{2}{|c|}{$1.50(1.0-2.0)$} & 1.850 & $\begin{array}{c}.06 \\
4\end{array}$ \\
\hline Consciousness & Conscious & 20 & 80.0 & 19 & 76.0 & .117 & .73 \\
\hline
\end{tabular}




\begin{tabular}{|c|c|c|c|c|c|c|c|}
\hline $\mathrm{N}(\%)$ & Disturbed & 5 & 20.0 & 6 & 24.0 & & 3 \\
\hline \multirow{2}{*}{$\begin{array}{l}\text { Blood pressure } \\
\mathrm{N}(\%)\end{array}$} & Hypotension & 18 & 72.0 & 21 & 84.0 & \multirow[t]{2}{*}{1.049} & .30 \\
\hline & Undetected & 7 & 28.0 & 4 & 16.0 & & 6 \\
\hline \multirow{3}{*}{$\begin{array}{l}\text { Pulse } \\
\mathrm{N}(\%)\end{array}$} & Normal & 8 & 32.0 & 8 & 32.0 & \multirow[t]{3}{*}{.366} & .83 \\
\hline & Tachycardia & 15 & 60.0 & 16 & 64.0 & & 3 \\
\hline & Undetected & 2 & 8.0 & 1 & 4.0 & & \\
\hline \multirow{2}{*}{$\begin{array}{l}\text { Respiratory rate } \\
\mathrm{N}(\%)\end{array}$} & Normal & 7 & 28.0 & 11 & 44.0 & \multirow[t]{2}{*}{1.389} & .23 \\
\hline & Tachypnea & 18 & 72.0 & 14 & 56.0 & & 9 \\
\hline \multirow{2}{*}{$\begin{array}{l}\text { Temperature } \\
\mathrm{N}(\%)\end{array}$} & Hypothermia & 4 & 16.0 & 2 & 8.0 & \multirow[t]{2}{*}{.189} & .66 \\
\hline & Normal & 21 & 84.0 & 23 & 92.0 & & 7 \\
\hline \multirow{2}{*}{$\begin{array}{l}\text { Vomiting } \\
\mathrm{N}(\%)\end{array}$} & No & 16 & 64.0 & 17 & 68.0 & \multirow[t]{2}{*}{.089} & .76 \\
\hline & Yes & 9 & 36.0 & 8 & 32.0 & & 5 \\
\hline \multirow{2}{*}{$\begin{array}{l}\text { Abdominal pain } \\
\mathrm{N}(\%)\end{array}$} & No & 21 & 84.0 & 23 & 92.0 & \multirow[t]{2}{*}{.771} & .66 \\
\hline & Yes & 4 & 16.0 & 2 & 8.0 & & 7 \\
\hline \multirow{8}{*}{$\begin{array}{l}\text { ECG } \\
\mathrm{N}(\%)\end{array}$} & Normal & 2 & 8.0 & 1 & 4.0 & \multirow[t]{8}{*}{4.308} & .83 \\
\hline & $\begin{array}{l}\text { Sinus } \\
\text { Tachycardia }\end{array}$ & 13 & 52.0 & 15 & 60.0 & & \multirow[t]{7}{*}{7} \\
\hline & Sinus Brady. & 2 & 8.0 & 1 & 4.0 & & \\
\hline & $\mathrm{AF}$ & 1 & 4.0 & 2 & 8.0 & & \\
\hline & Extrasystole & 1 & 4.0 & 3 & 12.0 & & \\
\hline & Inverted T-wave & 2 & 8.0 & 2 & 8.0 & & \\
\hline & S-T elevation & 3 & 12.0 & 1 & 4.0 & & \\
\hline & $\begin{array}{l}\text { Ventricular } \\
\text { tachycardia }\end{array}$ & 1 & 4.0 & 0 & 0.0 & & \\
\hline
\end{tabular}

P: $\mathrm{p}$ value for comparing between the studied groups $\quad *$ : Statistically significant at $\mathrm{p}<0.05$

Table (2): Base line laboratory characteristics of the study groups $(n=50)$

\begin{tabular}{|c|c|c|c|c|c|}
\hline & \multicolumn{2}{|c|}{ Groups } & \multicolumn{2}{|c|}{$\begin{array}{c}\text { Independent samples T } \\
\text { test }\end{array}$} \\
\hline & & $\begin{array}{c}\text { Supportive } \\
\text { A }(n=25)\end{array}$ & $\begin{array}{l}\text { Intervention } \\
\mathrm{B}(\mathrm{n}=25)\end{array}$ & $\mathrm{t}$ & $\mathrm{P}$ value \\
\hline \multirow[t]{4}{*}{ ALT } & Minimum & 10.0 & 7.0 & \multirow[t]{4}{*}{.310} & \multirow[t]{4}{*}{.758} \\
\hline & Maximum & 40.0 & 29.0 & & \\
\hline & Mean & 19.9 & 19.3 & & \\
\hline & SD & 7.6 & 6.0 & & \\
\hline \multirow[t]{2}{*}{ AST } & Minimum & 14.0 & 10.0 & \multirow[t]{2}{*}{1.058} & \multirow[t]{2}{*}{.071} \\
\hline & Maximum & 30.0 & 40.0 & & \\
\hline
\end{tabular}




\begin{tabular}{|c|c|c|c|c|c|}
\hline & Mean & 19.4 & 22.4 & & \\
\hline & SD & 3.6 & 7.3 & & \\
\hline Serum & Minimum & .5 & .5 & .212 & .833 \\
\hline creatinine & Maximum & 1.2 & 1.2 & & \\
\hline & Mean & .8 & .8 & & \\
\hline & SD & .2 & .2 & & \\
\hline Blood urea & Minimum & 15.0 & 18.0 & 1.41 & .164 \\
\hline & Maximum & 40.0 & 40.0 & & \\
\hline & Mean & 22.1 & 24.4 & & \\
\hline & SD & 5.8 & 5.6 & & \\
\hline Serum & Minimum & 135.5 & 133.0 & .166 & .869 \\
\hline sodium & Maximum & 147.0 & 149.0 & & \\
\hline & Mean & 140.4 & 140.2 & & \\
\hline & SD & 3.4 & 4.7 & & \\
\hline Serum & Minimum & 3.0 & 2.9 & 1.48 & .143 \\
\hline potassium & Maximum & 4.5 & 4.6 & & \\
\hline & Mean & 3.9 & 3.7 & & \\
\hline & SD & .4 & .4 & & \\
\hline $\mathrm{PH}$ & Minimum & 7.10 & 7.10 & .445 & .658 \\
\hline & Maximum & 7.50 & 7.40 & & \\
\hline & Mean & 7.21 & 7.23 & & \\
\hline & SD & .09 & .10 & & \\
\hline $\mathrm{P}_{\mathrm{a}} \mathrm{CO} 2$ & Minimum & 14.0 & 19.0 & 1.90 & .064 \\
\hline & Maximum & 44.0 & 44.0 & & \\
\hline & Mean & 30.7 & 35.0 & & \\
\hline & SD & 9.4 & 6.1 & & \\
\hline Oxygen & Minimum & 70.0 & 70.0 & .846 & .402 \\
\hline saturation & Maximum & 99.0 & 99.0 & & \\
\hline & Mean & 87.8 & 89.8 & & \\
\hline & SD & 8.1 & 7.9 & & \\
\hline HCO3 & Minimum & 6.3 & 8.5 & 1.52 & .134 \\
\hline & Maximum & 26.0 & 24.0 & & \\
\hline & Mean & 13.9 & 16.2 & & \\
\hline & SD & 5.5 & 5.1 & & \\
\hline
\end{tabular}

P: $p$ value for comparing between the studied groups

*: Statistically significant at $\mathrm{p}<0.05$ 
Table (3): Evaluation of plasma malondialdehyde, total antioxidant capacity, and reduced glutathione levels in the two studied groups at admission and $12 \mathrm{hrs}$ later

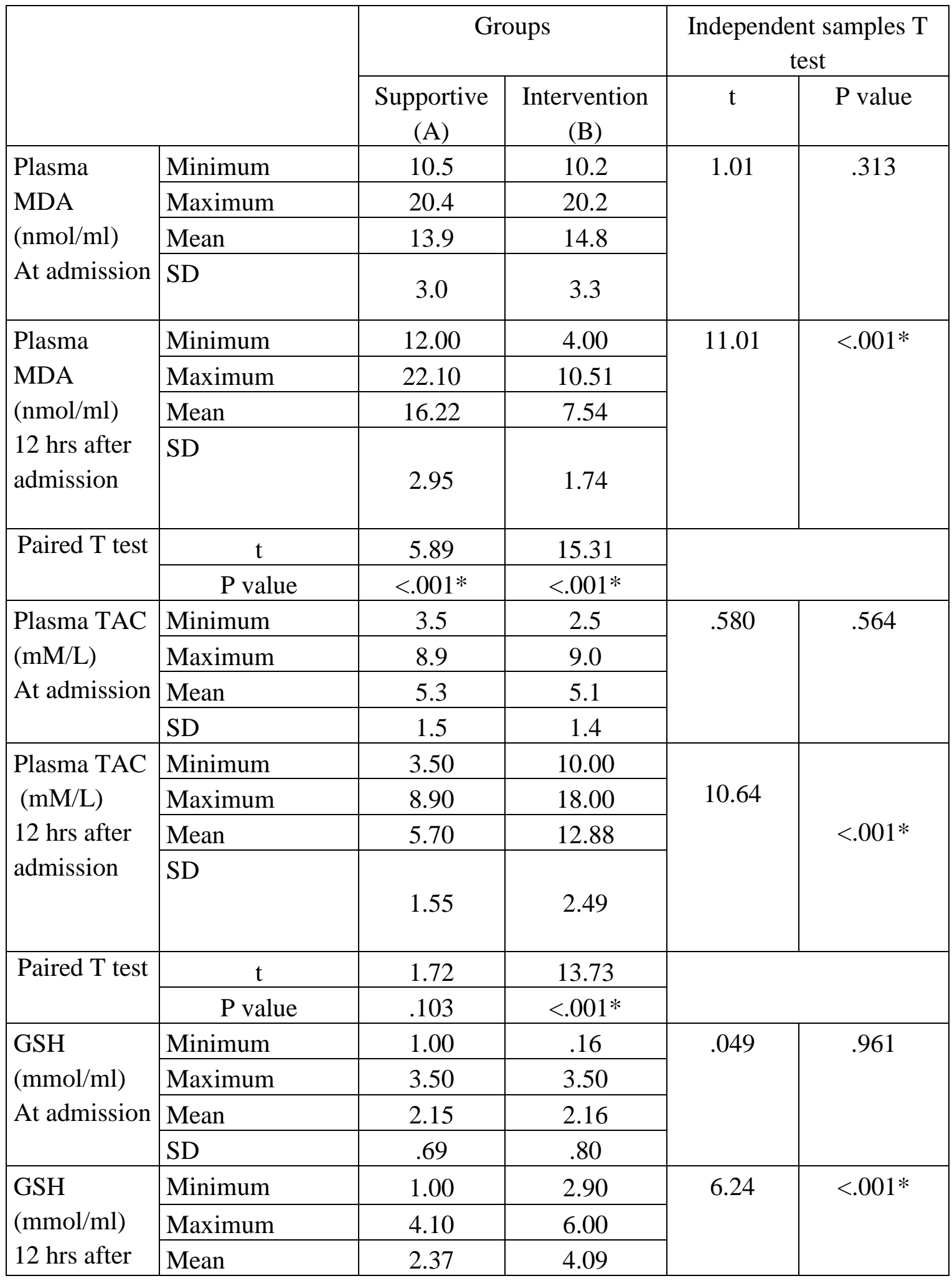




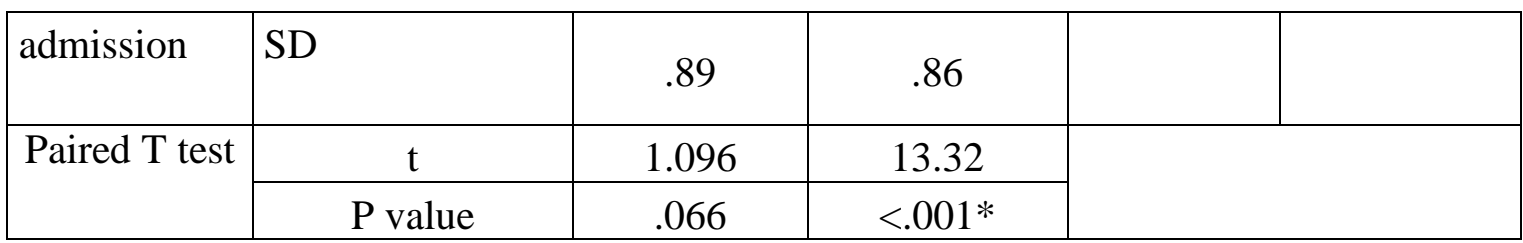

MDA: malondialdehyde, TAC: total antioxidant capacity, GSH: reduced glutathione

P: $p$ value for comparing between the studied groups

*: Statistically significant at $\mathrm{p}<0.05$

Table (4): Comparison of primary and secondary outcomes in the studied groups $(n=50)$

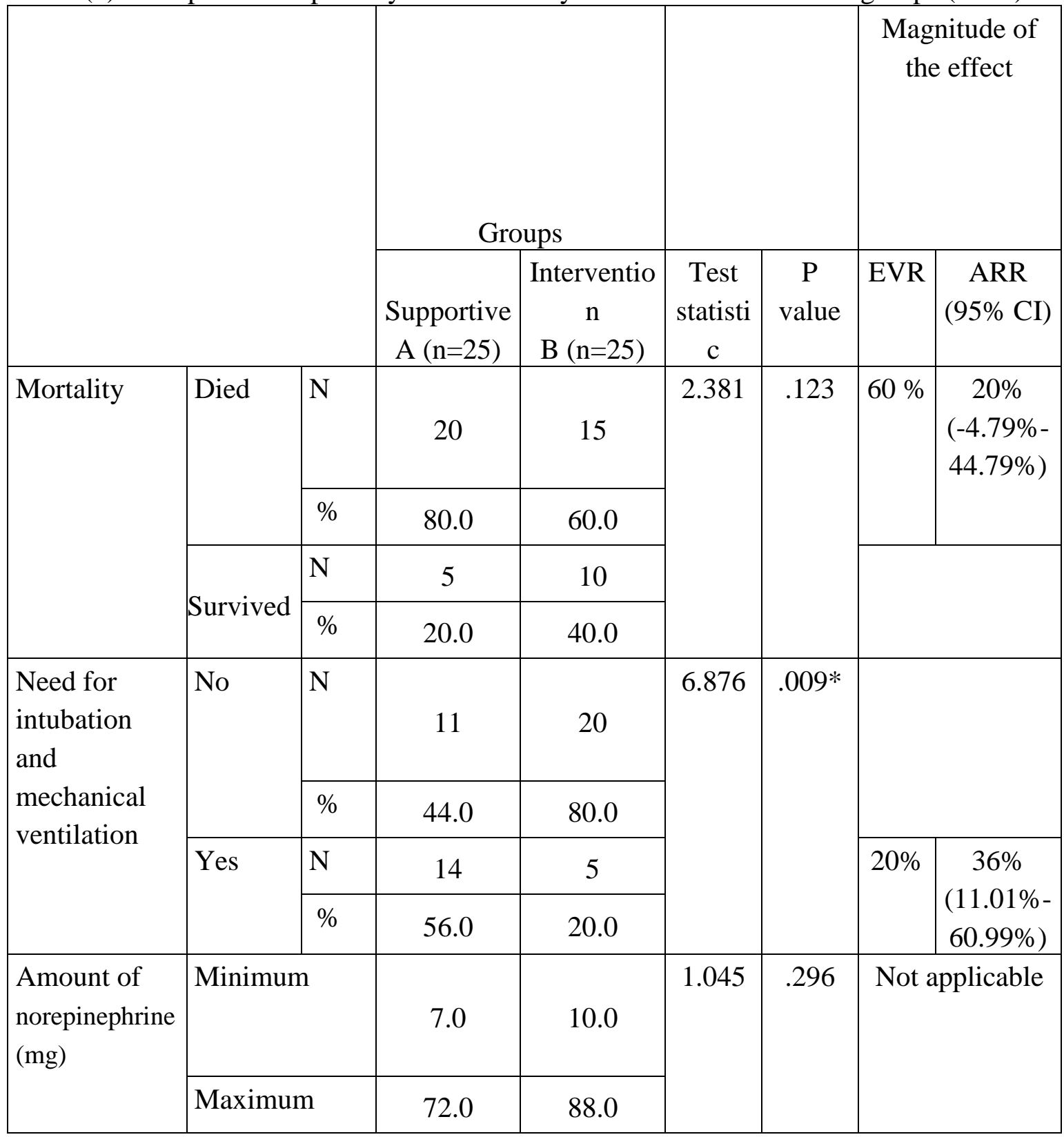




\begin{tabular}{|c|c|c|c|c|c|c|}
\hline & Median & 32.0 & 32.0 & & & \\
\hline & IQR & $10.0-40.0$ & $16.0-45.0$ & & & \\
\hline & Mean rank & 23.36 & 27.64 & & & \\
\hline Hospital stay & Minimum & 4.0 & 2.0 & 2.196 & $.028 *$ & Not applicable \\
\hline & Maximum & 144.0 & 168.0 & & & \\
\hline & Median & 14.0 & 36.0 & & & \\
\hline & IQR & $10.0-24.0$ & $18.0-48.0$ & & & \\
\hline & Mean rank & 20.98 & 30.02 & & & \\
\hline
\end{tabular}

P: $p$ value for comparing between the studied groups

*: Statistically significant at $\mathrm{p}<0.05$

EVR: Experiment event rate

ARR: Absolute risk reduction

CI: confidence interval.

Table (5): Comparison between survivors in the studied groups as regards need of mechanical ventilation and length of hospital stay $(n=15)$.

\begin{tabular}{|c|c|c|c|c|c|c|}
\hline \multirow{2}{*}{\multicolumn{3}{|c|}{\begin{tabular}{|l} 
Survivors \\
\end{tabular}}} & \multicolumn{2}{|c|}{ Groups } & \multicolumn{2}{|c|}{ Tests of significance } \\
\hline & & & $\begin{array}{c}\text { Supportive } \\
n=5\end{array}$ & $\begin{array}{l}\text { Intervention } \\
n=10\end{array}$ & $\begin{array}{c}\text { Test } \\
\text { statistic }\end{array}$ & $\mathrm{P}$ value \\
\hline \multirow{4}{*}{$\begin{array}{l}\text { Need for } \\
\text { intubation and } \\
\text { mechanical } \\
\text { ventilation }\end{array}$} & \multirow[t]{2}{*}{ No } & $\mathrm{N}$ & 4 & 9 & \multirow[t]{4}{*}{.288} & \multirow[t]{4}{*}{.591} \\
\hline & & $\%$ & 80.0 & 90.0 & & \\
\hline & \multirow[t]{2}{*}{ Yes } & $\mathrm{N}$ & 1 & 1 & & \\
\hline & & $\%$ & 20.0 & 10.0 & & \\
\hline \multirow{5}{*}{$\begin{array}{l}\text { Hospital stay } \\
\text { (hrs) }\end{array}$} & \multicolumn{2}{|c|}{ Minimum } & 60.0 & 24.0 & \multirow[t]{5}{*}{3.017} & \multirow[t]{5}{*}{$.001 *$} \\
\hline & \multicolumn{2}{|c|}{\begin{tabular}{|l|} 
Maximum \\
\end{tabular}} & 144.0 & 60.0 & & \\
\hline & \multicolumn{2}{|c|}{ Median } & 90.0 & 44.0 & & \\
\hline & \multicolumn{2}{|c|}{ IQR } & $72.0-96.0$ & $36.0-54.0$ & & \\
\hline & \multicolumn{2}{|c|}{ Mean rank } & 12.90 & 5.55 & & \\
\hline
\end{tabular}

P: $p$ value for comparing between the studied groups

*: Statistically significant at $\mathrm{p}<0.05$ 
Table (6): Comparison between non-survivors in the studied groups as regards need of mechanical ventilation and length of hospital stay $(\mathrm{N}=35)$

\begin{tabular}{|c|c|c|c|c|c|c|c|c|}
\hline \multirow{2}{*}{\multicolumn{3}{|c|}{ Non-survivors }} & \multicolumn{2}{|c|}{ Groups } & \multicolumn{2}{|c|}{$\begin{array}{c}\text { Tests of } \\
\text { significance }\end{array}$} & \multicolumn{2}{|c|}{$\begin{array}{c}\text { Magnitude of } \\
\text { the effect }\end{array}$} \\
\hline & & & $\begin{array}{c}\text { Supportiv } \\
\text { e } \\
\mathrm{N}=20\end{array}$ & $\begin{array}{c}\text { Interventio } \\
n \\
\mathrm{~N}=15\end{array}$ & $\begin{array}{c}\text { Test } \\
\text { statistic }\end{array}$ & $P$ value & EVR & $\begin{array}{c}\text { ARR } \\
(95 \% \\
\text { CI })\end{array}$ \\
\hline \multirow{4}{*}{$\begin{array}{l}\text { Need for } \\
\text { intubation } \\
\text { and } \\
\text { mechanical } \\
\text { ventilation }\end{array}$} & \multirow[t]{2}{*}{ No } & $\mathrm{N}$ & 7 & 11 & \multirow[t]{4}{*}{5.042} & \multirow[t]{4}{*}{$.025^{*}$} & & \\
\hline & & $\%$ & $35.0 \%$ & $73.3 \%$ & & & & \\
\hline & \multirow[t]{2}{*}{ Yes } & $\mathrm{N}$ & 13 & 4 & & & \multirow{2}{*}{$\begin{array}{c}26.7 \\
\%\end{array}$} & $38.33 \%$ \\
\hline & & $\%$ & $65.0 \%$ & $26.7 \%$ & & & & $\begin{array}{l}(7.71 \%- \\
68.96 \%)\end{array}$ \\
\hline \multirow[t]{5}{*}{ Hospital stay } & \multicolumn{2}{|c|}{ Minimum } & 4.00 & 2.00 & \multirow[t]{5}{*}{2.39} & \multirow[t]{5}{*}{$.016^{*}$} & \multirow{5}{*}{\multicolumn{2}{|c|}{ Not applicable }} \\
\hline & \multicolumn{2}{|c|}{ Maximum } & 30.00 & 168.00 & & & & \\
\hline & \multicolumn{2}{|c|}{ Median } & 12.00 & 23.00 & & & & \\
\hline & \multicolumn{2}{|l|}{ IQR } & $\begin{array}{l}7.00- \\
16.00 \\
\end{array}$ & $\begin{array}{c}14.00- \\
40.00 \\
\end{array}$ & & & & \\
\hline & \multicolumn{2}{|c|}{ Mean rank } & 14.42 & 22.77 & & & & \\
\hline
\end{tabular}

P: $p$ value for comparing between the studied groups

*: Statistically significant at $\mathrm{p}<0.05$

EVR: Experiment event rate

ARR: Absolute risk reduction

CI: confidence interval.

\section{DISCUSSION}

This study was phase II randomized clinical trial to disclose the safety and efficacy of early L-carnitine administration as an added treatment in acute AlP poisoning. At cellular levels, this study revealed the antioxidant effect of L- carnitine in the form of significant reduction in Malondialdehyde levels accompanied with significant increase in the total antioxidant capacity and reduced glutathione activity only in the L-carnitine-treated patients. Concerning outcome of the studied patients, the rate of deaths in patients on L-carnitine therapy was diminished but it did not reach a significant level. Additionally, patients received adjuvant L- carnitine regimen showed significant reduction in the need for intubation and mechanical ventilation. Whereas, they required a significantly longer duration of hospital stay. However, survivors that received L-carnitine therapy substantially showed shorter duration of hospital stay. It's worth to mention that L-carnitine administration of was safe with no reported adverse effects.

In the current study, assessment of the oxidative stress biomarkers $12 \mathrm{hrs}$ after admission showed effective termination of lipid peroxidation indicated by significant reduction in the plasma MDA levels in patients received L-carnitine treatment. Alternatively, 
patients who were given only the conventional supportive treatment exhibited continuous propagation of oxidative damage of free fatty acids denoted by significant increase in the MDA levels. This was accompanied with significant elevation in the total antioxidant capacity and reduced glutathione levels in patients on Lcarnitine therapy. This emphasizes the involvement of glutathione in phosphine induced oxidative toxicity and the capability of L-carnitine to replenish the antioxidant defenses against PH3. Comparable findings have been shown in an animal study where, L-carnitine administration in AlP -intoxicated rats has significantly attenuated the oxidative stress and improved mitochondrial function and energy production (Baghaei et al., 2016). Beneficial antioxidant effects of L-carnitine have been demonstrated in toxicities caused by arsenic (Sepand et al., 2016) and cadmium (Abu-El-Zahab et al., 2019).

Though the exact mechanisms of AlP poisoning are not known, various animal and human studies had shown that AlP poisoning induces generation of superoxide radicles, cellular peroxides, hydrogen peroxide, and MDA while, it inhibits the antioxidant enzymes like glutathione, catalase and peroxidase (Anand et al., 2012, Mehrpour et al., 2014, Anand et al., 2013). Thereby, AlP induces oxidative stress and cellular damage via increasing lipid peroxidation, protein denaturation and hypoxic damage (Yousef et al., 2015).

It is clear that oxidative stress is one of the main mechanisms of AlP induced organ damage. This has encouraged many researchers to investigate the possible role of antioxidants therapy in improving the prognosis of such fatal type of poisoning (Tehrani et al., 2013).

L-carnitine is an essential cofactor in fatty acid metabolism which is the primary source of energy for cardiac muscles. It increases long-chain fatty acids and activated acetate transport across the inner mitochondrial membrane (Schönfeld and Wojtczak, 2016).

Furthermore, it has been reported that L-carnitine therapy added to aggressive supportive care has rescued two cases presented by severe myocardial cell dysfunction and shock caused by AlP ingestion. Each of them has exhibited improvement of cardiac parameters, maintenance of vital signs that ended by survival(Elabbassi et al., 2014, Sumit and Vishnu, 2015). Hence, this work was implemented to validate the efficacy of L-carnitine addition in severe cases of AlP poisoning presented early with shock within $3 \mathrm{hrs}$ of toxic exposure.

Effects of early L-carnitine administration on outcomes of AlP poisoned patients in the present study seems promising. There was insignificant reduction in death rate in patients received L-carnitine (60\%) compared with patients received only the routine supportive care $(80 \%)$.

Absence of significant effects of L-carnitine on patient's survival might be attributed to the nature of our study population where only severe cases presented early with shock were recruited. Additionally, It's recognized that AlP poisoning is characterized by high mortality rate varies from $35 \%$ - 
91\% within the first $24 \mathrm{hrs}$ (Alnasser et al., 2018). This high rate of deaths might be attributed to unidentified mechanisms of toxicity that could explain the observed rapid progression in the course of this poisoning which often ends with death (Singh et al., 2015).

To the best of our knowledge, no previous RCTs evaluated efficacy of Lcarnitine in AlP poisoning. Bhalla et al. (2017) has stated that $\mathrm{N}$-acetylcysteine (NAC) IV infusion at $150 \mathrm{mg} / \mathrm{kg}$ over 1 $\mathrm{h}$, followed by $50 \mathrm{mg} / \mathrm{kg}$ over $4 \mathrm{hrs}$, and another $100 \mathrm{mg} / \mathrm{kg}$ over $16 \mathrm{hrs}$ did not show any survival benefits in severe cases of AlP poisoning. Comparable results have also been reported where a randomized controlled trial of NAC infusion at a rate of $300 \mathrm{mg} / \mathrm{kg}$ for 20 hrs has showed insignificant reduction in mortality rate $(30.4 \%$ compared to $43.5 \%$ in the control group) despite the observed improvement in blood pressure and oxygen saturation of the patients on NAC therapy (Taghaddosinejad et al., 2016).

Even with the improvement of the antioxidant status and MDA levels after $\mathrm{N}$-acetylcysteine addition to supportive care of AlP poisoned patients (Tehrani et al., 2013), there was non-significant reduction in the rate of their deaths.

Death in AlP poisoning is mainly due to refractory cardiogenic shock, where most patients display profound drop in blood pressure which is not responsive to the usual supportive treatment (Mohan et al., 2016). Aluminium phosphide toxicity inhibits cytochrome $\mathrm{c}$ oxidase in the mitochondria of cardiomyocyte and interferes with the electron transport chain resulting in toxic myocardial necrosis similar to what occurs during ischemia Sciuto et al., (2016). Furthermore, Noordali et al. (2017) have reported that myocardial hypoxia adversely affecting electrical conduction and muscle contraction due to accumulation of long-chain acyl-CoA esters. In this regard, Song et al. (2017) have demonstrated that L-carnitine use in ischemic hearts has preserved mechanical function with a significant reduction of left ventricular dilatation.

Patients with AlP poisoning frequently requires endotracheal intubation and intensive care unit admission for mechanical ventilation since AlP causes hypoxia, adult respiratory distress syndrome, and disturbed conscious level Farzaneh et al., (2018). In this regard, the current study demonstrated significant reduction in the need for intubation and mechanical ventilation in patients received L-carnitine regimen (20\% vs $56 \%$ in the control group). Certainly, this effect of L- carnitine saves the hospital resources, minimizes costs and the mechanical ventilation related complications.

Another beneficial effect of the adjuvant use of L-carnitine in the present work is significant reduction in the length of hospital stay of survivors (44 hrs vs $99 \mathrm{hrs}$ in the control group). Consistent with this finding, Oami et al., (2018) have demonstrated depletion of carnitine in critically ill patients and they have suggested potential benefits of L-carnitine therapy in these patients. Non-survivors in the intervention group showed significantly longer hospital stay compared to patients received only the supportive 
management (23 vs 12 hrs). actually, patients were stabilized with L-carnitine therapy but unexpectedly for unknown mechanism rapid deterioration and death occurs.

This study has strengths of being a randomized controlled clinical trial that was applied on a suitable sample size. Additionally, it considered the rapidly progressive course of AlP poisoning where only patients presented with shock within $3 \mathrm{hrs}$ of toxic exposure were eligible. Though, it remains a single center study that necessitate further validation in other poison control centers.

\section{REFERENCES}

\section{Abu-El-Zahab,H. S., Hamza R. Z., Montaser M. M., El-Mahdi M. M., and Al-HarthiW. A. (2019): Antioxidant, antiapoptotic, antigenotoxic, and hepatic ameliorative effects of L- carnitine and selenium on cadmium-induced hepatotoxicity and alterations in liver cell structure in male mice. Ecotoxicology and environmental safety, 173, 419-}

Alnasser S., hussain SM, Kirdi TS and Ahmed A (2018): Aluminum phosphide poisoning in saudi arabia over a nine-year period. annals of saudi medicine, 38, 277-283.

Anand R., kumari P., kaushal A., Bal A., Wani WY., Sunkaria A., et al, (2012): Effect of acute aluminum phosphide exposure on rats: a biochemical and histological correlation. toxicol lett, 215, 62-9.

\section{CONCLUSION:}

It could be deduced that early administration of L-carnitine IV infusion besides the conventional treatment in AlP poisoned patient has valuable effects. It significantly attenuated oxidative stress and lipid peroxidation. Additionally, L- carnitine therapy achieved favorable outcomes denoted by significant reduction in the need for intubation and mechanical ventilation. However, its role in minimizing mortality was not evident. Further, the use of L- carnitine was safe with no reported side effects.

Anand R., Sharma DR., Verma D., Bhalla A., Gill KD. and Singh S.( 2013): Mitochondrial electron transport chain complexes, catalase and markers of oxidative stress in platelets of patients with severe aluminum phosphide poisoning. hum exp toxicol, 32, 807-16.

Badawi S., Alseidy A., Alfeki A., Mansour M. and Abd el-hamid A,(2018): Metal phosphide poisoning in menoufia university hospitals. 31, 816-821.

Baghaei A., Solgi R., Jafari A., Abdolghaffari AH , Golaghaei A., Asghari MH., et al , (2016): Molecular and biochemical evidence on the protection of cardiomyocytes from phosphine-induced oxidative stress, mitochondrial dysfunction and apoptosis by acetyl-1carnitine. environ toxicol pharmacol, 42, 30-7. 
Bhalla A., Jyothinath P. and Singh S. , (2017): Antioxidant therapy in patients with severe aluminum phosphide poisoning: a pilot study. indian journal of critical care medicine : peer-reviewed, official publication of indian society of critical care medicine, $21,836-840$.

Chugh SN., Ram S., Chugh K. and Malhotra KC. , (1989): Spot diagnosis of aluminium phosphide ingestion: an application of a simple test. $\mathrm{j}$ assoc physicians india, 37, 21920.

Doig GS., Simpson F. and Delaney A. (2005): A review of the true methodological quality of nutritional support trials conducted in the critically ill: time for improvement. anesth analg, 100, 527-33.

Dorooshi G., Zoofaghari S., mood NE.and Gheshlaghi F. (2018): A newly proposed management protocol for acute aluminum phosphide poisoning. journal of research in pharmacy practice, 7 , 168-169.

Elabbassi W., Chowdhury MA. and Fachtartz AAN( 2014): Severe reversible myocardial injury associated with aluminium phosphide toxicity: a case report and review of literature. journal of the saudi heart association, 26, 216-221.

Farahani M V., Soroosh D. and Marashi S. M. (2016): Thoughts on the current management of acute aluminum phosphide toxicity and proposals for therapy: an evidence-based review. indian journal of critical care medicine : peer-reviewed, official publication of indian society of critical care medicine, 20, 724-730.

Gouda A S., El-nabarawy N A. and Ibrahim S F (2018): Moringa oleifera extract (lam) attenuates aluminium phosphide-induced acute cardiac toxicity in rats. toxicology reports, 5, 209-212.

Hashemi-Domeneh B., Zamani N., Hassanian-moghaddam H.,Rahimi M., Shadnia S., Erfantalab P. etal. (2016): A review of aluminium phosphide poisoning and a flowchart to treat it. arh hig rada toksikol, 67, 183193.

Koracevic D., Koracevic G., Djordjevic V., Andrejevic S. and Cosic V. (2001): Method for the measurement of antioxidant activity in human fluids. journal of clinical pathology, 54, 356361 .

Mehrpour O., Abdollahi M. and Sharifi M.D. (2014): Oxidative stress and hyperglycemia in aluminum phosphide poisoning. $\mathrm{j}$ res med sci, 19, 196.

Navabi SM., Navabi J., Aghaei A., Shaahmadi $Z$. and Heydari R.(2018): Mortality from aluminum phosphide poisoning in kermanshah province, iran: characteristics and predictive 
factors. epidemiology and health, 40, e2018022-e2018022.

Ohkawa H., Ohishi N. and Yagi K. (1979): Assay for lipid peroxides in animal tissues by thiobarbituric acid reaction. anal biochem, 95, 351-8.

Schönfeld P. and Wojtczak l. (2016): Short- and medium-chain fatty acids in energy metabolism: the cellular perspective. journal of lipid research, 57, 943-954.

Sciuto A M., Wong B J., Martens ME., Hoard-Fruchey $H$. and Perkins M W. (2016): Phosphine toxicity: a story of disrupted mitochondrial metabolism. annals of the new york academy of sciences, 1374 , 41-51.

Singh I., Gupta K., Agarwal S., Bansal M., Samad A. and Kalra P. (2015): clinical efficacy of oral gabapentin versus clonidine for preemptive analgesia in knee arthroplasty under epidural anesthesia with $0.75 \& \# 37$; ropivacaine \&\#8211; a comparative study. journal of mahatma gandhi institute of medical sciences, , 20, 15-19.

Song x., Yang Z., Rong J., Cai W. and Zhou H. (2017): Efficacy and safety of 1-carnitine treatment for chronic heart failure: a metaanalysis of randomized controlled trials. biomed research international, 2017, 62748546274854 .
Sumit B. and Vishnu P. (2015): Rare survival after severe aluminium phosphidepoisoiningafter myocarditiswith 1-carnitine and steroid. international journal of pharmacy and pharmaceutical sciences, 7 .

Taghaddosinejad F., Farzaneh E., Ghazanfari-Nasrabad M., Eizadi-Mood N., Hajihosseini M. and Mehrpour O. (2016): The effect of n-acetyl cysteine (nac) on aluminum phosphide poisoning inducing cardiovascular toxicity: a casecontrol study. springerplus, 5, 1948.

Tehrani H., Halvaie Z., Shadnia S., Soltaninejad K. and Abdollahi M (2013): Protective effects of n-acetylcysteine on aluminum phosphide-induced oxidative stress in acute human poisoning. clin toxicol (phila), 51, 23-8.

Tietze F. (1969): Enzymic method for quantitative determination of nanogram amounts of total and oxidized glutathione: applications to mammalian blood and other tissues. anal biochem, 27, 502-22.

Yousef M I., Soliman NF. and Eldemerdash F M. (2015): Aluminium phosphide-induced hepato-nephrotoxicity and oxidative damage in rats: the protective effect of $\alpha$-lipoic acid. the open conference proceedings journal,, 6, 18-23. 


\section{الملخص العربي}

العلاج المبكر ب لكارنيتين في التسمم الحاد الثديد بفوسفيد الألومنيوم: تجربة سريرية عشوائية منضبطة

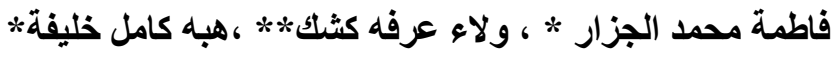

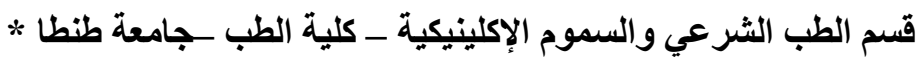

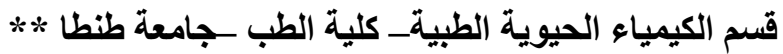

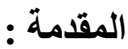

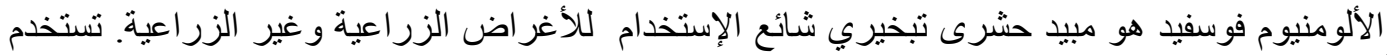

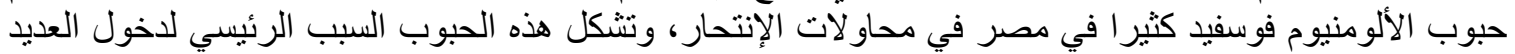

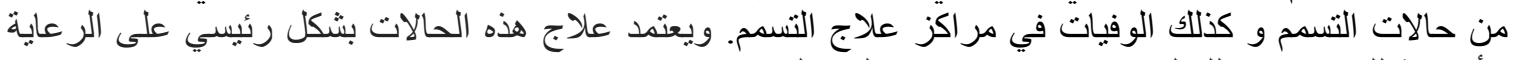

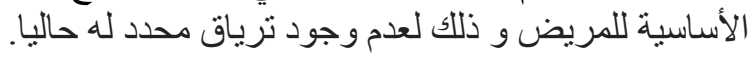

الهذف من هذه الدراسة:

تقييم التأثير العلاجي و سلامة الإستخدام المبكرلدواء لـ ـ كارنيتين كعلاج مساعد في التسمم الحاد الثديد

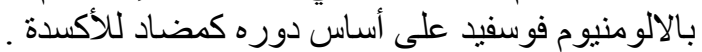

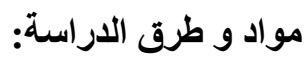



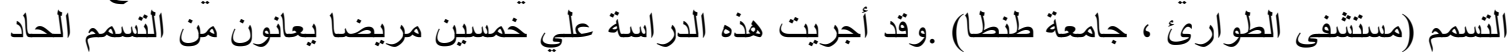



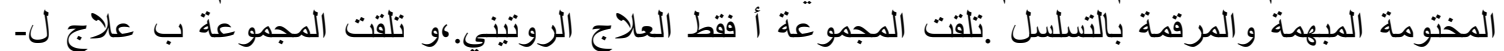

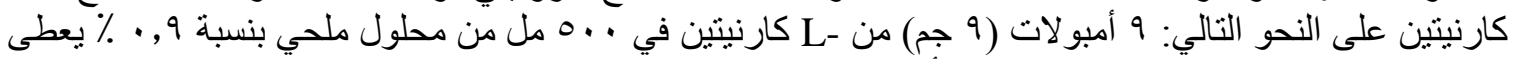

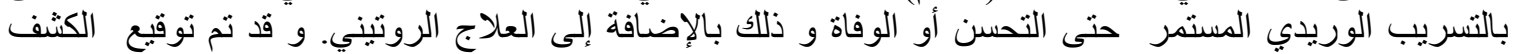

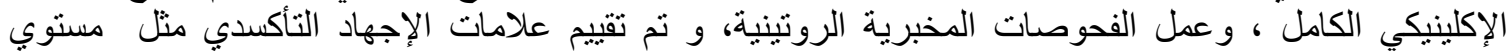

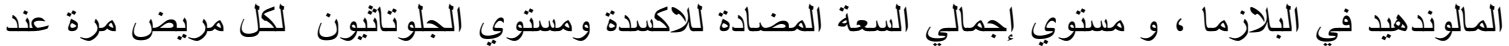
الدخول مباشرة و أخري بعد مرور بالئ و ال ساعة.

النتائج:

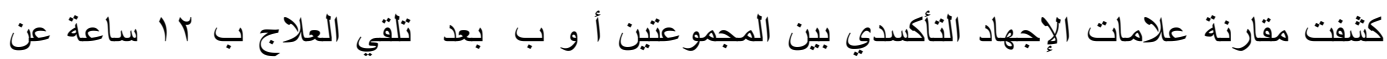

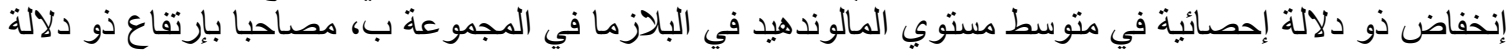

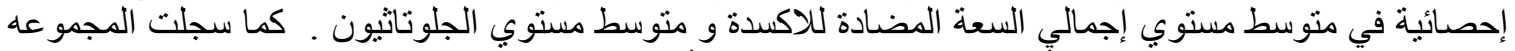





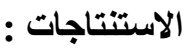

وخلصت نتائج الدراسة إلى أن الإستخدام المبكر لدواء ل ـكارنيتين عن طريق الوريد فعال و آمن كعلاج مساعد في حالات التسمم الحاد الثنديد بالالومنيوم فوسفيد. 